\section{Semicarbazide as potential source of formaldehyde and nitric oxide formation}

\author{
Nely Latyshko, Olga Gudkova, \\ Mykola Dmytrenko
}

Department of Metabolism Regulation, Palladin Institute of Biochemistry,

National Academy of Science of Ukraine, Kyiv, Ukraine

\section{Abstract}

Growing evidence that the potential carcinogen, semicarbazide, may get into the human body makes especially important of knowledge for its metabolic fate. While the general agreement that semicarbazide is aldehyde trapping agent and inhibitor of semicarbazide sensitive amine oxidase, which activity increases in blood and body tissues in pathological states, there is assumption that at least one clearans mechanism must operate in vivo. We supposed that semicarbazide may be metabolysed by the members of cytochrome P-450 (CYP-450) family in liver microsomes generating dangerous products. Using difference spectrometry we have found that semicarbazide-induced spectral changes reflect its binding to the active site of CYP-450. To identify the products of semicarbazide decomposition, $7.5 \mathrm{mM}$ semicarbazide was incubated with rat liver microsomes. The concentrations of formaldehyde, nitric oxide on the basis of accumulation of nitrite in the medium, and ammonium were determined by microplate-based spectrophotometry and fluorometry, accordingly. There was net increase in the concentrations of the products during incubation in comparison with control to the extent of $22.04 \pm 7.1$ for formaldehyde and $11.29 \pm 1.91$ for nitric oxide $\mathrm{mol} / \mathrm{mg}$ protein within $15 \mathrm{~min}$. Formaldehyde and nitric oxide formations were additionally confirmed by using their traps. Dimedone, formaldehyde trap, decreased its amount in the reaction mixture by $55 \%$, whereas irondithiocarbamate complex, nitric oxide trap, by $52 \%$. The results suggest that semicarbazide transformation is viewed as two important pathways: one, yielding formaldehyde, and other, producing nitric oxide and ammonium. These hazard products are the reasons for semicarbazide toxicity.

\section{Introduction}

Semicarbazide (SC) belongs to a family of chemicals called hydrazines, that might be a factor in certain human deseases induction due to its presence in some food and carcinogenic potency on animal models. Although the potential side effects of SC are of serious concern, $\mathrm{SC}$ is used in certain pesticide formulations and industrial applications. $\mathrm{SC}$ is used as a blowing agent in rubber products and foamed polyethylene that are permitted for food packaging applications. In a number of countries, SC is also approved as a food additive, bleaching agent for cereal flour and as a dough conditioner. Furthermore, it is used as therapeutic for healing some deseases including cancer. ${ }^{1}$ Semicarbazide can reduce inflammatory response and may protect against the progressive vascular complications. It also can reduce pain. Clinical use of SC is based on the ability to scavenge aldehydes as well as to inhibit enzymes, such as semicarbazide-sensitive amine oxidase (SSA0), whose activity was found significantly increased in blood and tissues in some pathologies. ${ }^{2}$ A clear majority of toxicity and carcinogenicity studies involve the administration of SC into various animal species. Some of the SC side effects listed included lathyrism (a collagen cross linking disease) in rats, ${ }^{3}$ death and foetus retardation in hamsters, tissue abnormalities such as haemorrhaging in brain, liver and intestine, ${ }^{4}$ abnormalities in bone formation, and underdeveloped testes in rats injected with low doses of SC hydrochloride saline solution during the gestation. SC induced osteochondral and vascular lesions, it had carcinogenic features and may also be genotoxic and potentially dangerous for human health. But the mechanism of this substance toxicity is not well understood. Information on marked increase of ammonia excretion (approximately four-fold) over the 24 hours in rats following $\mathrm{SC}^{5}$ has generated the idea of semicarbazide metabolism with ammonia as a degradation product. Besides, other researchers found that $\mathrm{SC}$ may give rise to both formaldehyde (FA) and nitrogen in in vitro studies using $\mathrm{SC}$ as formaldehyde trapping agent. ${ }^{6}$ Bearing in the mind these facts we supposed that $\mathrm{SC}$ may be metabolized by members of cytochrome P-450 (CYP-450s) superfamily in the liver. We suppose basing on some data and its structural formula that SC may be metabolized, forming toxic products which are the reasones of its toxicity.

The oxidation products may include formaldehyde, as well as ammonium and nitric oxide (NO). FA is extremely reactive and capable to forming Schiff $s$ bases with free amino or amide groups of proteins, which subsequently form methylene bridges. This was thought to contribute to protein misfolding associated with many pathological conditions. ${ }^{7}$ Ammonium is both caustic and hazardous. NO is also involved in many physiological and pathological processes. Chronic expression of NO is associated with various carcinomas and
Correspondence: Nely Latyshko, Palladin Institute of Biochemistry National Academy of Science of Ukraine, Department of Metabolism Regulation, Leontovicha str. 9, Kyiv, 01601, Ukraine. Tel. +380.44 .2344345 - Fax: +380.44 .2796365 .

E-mail: latn@biochem.kiev.ua

Key words: semicarbazide, semicarbazide-sensitive amine oxidase, formaldehyde, nitric oxide, ammonium, dimedone.

Aknowledgments: we thank Dr. S.G. Shandrenko for the critical comments and helpful discussions during manuscript preparation. In memoriam Mykola Dmytrenko.

Contributions: NL, study design, NO and ammonium determination and spectral assays, data analysis, manuscript drafting; $\mathrm{OG}$, experiments design, microsomes preparation, FA and protein content estimations, statistical analyses, manuscript drafting; MD, idea design, pilot experiments participation.

Received for publication: 6 February 2012.

Accepted for publication: 15 February 2012.

This work is licensed under a Creative Commons Attribution NonCommercial 3.0 License (CC BYNC 3.0).

(C) Copyright N. Latyshko et al., 2012

Licensee PAGEPress, Italy

Drugs and Therapy Studies 2012; 2:e9

doi:10.4081/dts.2012.eg

inflammatory states including juvenile diabetes, multiple sclerosis, arthritis and ulcerative colitis. $^{8}$

In this study, we used in vitro approach to investigate whether SC is a substrate for liver CYP-450s. The goal of the work was to elucidate the possibility of SC metabolization by rat liver microsomes (CYP-450s) and to find the products formed.

\section{Materials and Methods}

\section{Materials}

$\mathrm{N}$-nitrosodimethylamine (NDMA), semicarbazide hydrochloride, $\mathrm{NADF}^{+}$, isocitric acid, isocitrate dehydrogenase from porcine heart, sodium diethylditiocarbamate trihydrate, $N$-(1naphthyl) ethylenediamine dihydrochloride, $O$ phthaldialdehyde, Bradford reagent and bovine serum albumin were obtained from Sigma Chemical Co. 2,4-pentanedione and acetic acid, ammonium salt were obtained from Acros Organics. 2-mercaptoethanol was obtained from Ferac Berlin. All other chemicals were of the highest grade commercially available. 
Preparation of rat liver microsomes

All manipulations with animals before the beginning of isolation of livers were performed in accordance with the Helsinki Declaration of 1975 (revised in 1983) and national requirements for the care and use of laboratory animals. White mongrel female-rats (100-160 g) were used in these studies. Before experiment Nembutal anesthetic was used. After sacrifice of the animals by decapitation, the livers were removed on ice, and perfused with fresh icecold $0.15 \mathrm{M} \mathrm{KCI}$ through the hepatic veins to remove blood. All further steps were performed at $0-4^{\circ} \mathrm{C}$. The differential centrifugation method was employed for isolation of microsomal fractions. ${ }^{6,9,10}$ Perfused liver was homogenized in $10 \mathrm{vol} / \mathrm{g}$ of wet tissue weight of $10 \mathrm{mM}$ Tris-HCl buffer ( $\mathrm{pH} 7.2$ ) containing $0.25 \mathrm{M}$ sucrose. The homogenate was filtered through 2 layers of surgical gauze and centrifuged at $700 \mathrm{~g}$ for $10 \mathrm{~min}$. The supernatant was centrifuged at $9000 \mathrm{~g}$ for $20 \mathrm{~min}$ and at 105,000 g for 1 hour. The pellet was suspended in the same buffer containing $0.25 \mathrm{M}$ sucrose and centrifuged at $105,000 \mathrm{~g}$ for 1 hour. The microsomal pellets were resuspended in the buffer ( $1 \mathrm{~mL}$ of buffer per $1 \mathrm{~g}$ of wet liver), frozen and stored in aliquots ( $1.5-\mathrm{mL}$ portions) at $-80^{\circ} \mathrm{C}$ until use.

\section{Protein estimation}

The protein concentration was determined by the method of Bradford. ${ }^{11}$

\section{Vizible spectroscopy}

All spectra were carried out with spectrophotometer $\mu \mathrm{Qx200}$ (BioTek Instruments, Inc., USA). The wavelength range typically encompassed 350 to $500 \mathrm{~nm}$ and readings averaged over 3-5 scans were taken in 1-nm steps. The experiments were carried out at room temperature in matched cuvettes for $1 \mathrm{~cm}$ wavelength readings containing microsomes diluted with $10 \mathrm{mM}$ Tris-HCl buffer ( $\mathrm{pH}$ 7.2) to a protein concentration of $0.4-0.9 \mathrm{mg} / \mathrm{mL}$. The SC solutions in the same buffer were added to $1 \mathrm{~mL}$ of a suspension of microsomes up to a final volume of not more than $1 \%$ of the total volume of the solution.

\section{Semicarbaside metabolism assays using rat liver microsomes}

Reactions were performed in $5 \mathrm{mM}$ Tris-HC buffer ( $\mathrm{pH} 7.2$ ) saturated with oxygen, containing $5 \mathrm{mM} \mathrm{MgCl} 2,4.5-6 \mathrm{mg}$ microsomal protein (1.5 mL of microsomal fraction), $7.5 \mathrm{mM}$ semicarbazide or $5 \mathrm{mM} \mathrm{N}$-nitroso-dimethylamine as a substrate, and an Nicotinamide Adenine Dinucleotide Phosphate Hydrogen (NADPH) generating system consisting of 0.5 $\mathrm{mM} \mathrm{NADF}{ }^{+}, 7.5 \mathrm{mM}$ isocitric acid, and $1 \mathrm{U} / \mathrm{mL}$ isocitrate dehydrogenase in a final volume 2.2 $\mathrm{mL}$. Tubes were tightly stopped to avoid evapo- ration and air contamination. The vials were incubated in a water-bath shaker at $37^{\circ} \mathrm{C}$ for 30 min. At 0,15 and $30 \mathrm{~min}, 100 \mathrm{~L}$ of reaction mixture was removed and added to $10 \mathrm{~L}$ of cold $30 \% \mathrm{ZnSO}_{4}$ and the protein was removed by centrifugation at $2500 \mathrm{~g}$ for $10 \mathrm{~min}$. Controls were also run in this way but without substrate. For formaldehyde trapping, reactions were performed in the similar conditions with addition of $5 \mathrm{mM}$ dimedone as formaldehyde trap in the medium. ${ }^{12}$ Trapping of NO with the iron-dithiocarbamate $\left(\mathrm{Fe}^{+2}\right.$-DTC) complex was employed in the assay. ${ }^{13}$ Reactions were performed as above with sequential addition of sodium diethylditiocarbamate $(5 \mathrm{mM})$, and ferrous sulfate $(5 \mathrm{mM})$ in the reaction medium. Assays were run in duplicate.

\section{Determination of formaldehyde formation}

The colorimetric estimation of FA by means of the Hantzsch reaction was applied to microplate reader. For the determination of FA the supernatant solution was mixed with equal volume of Nash reagent, ${ }^{14}$ and incubated for 40 $\min$ at $37^{\circ} \mathrm{C}$. The absorbance was read at 412 $\mathrm{nm}$, a solution similarly treated, but without substrate and microsomes, was used as the blank. Standards contained known quantities of FA in the buffer.

\section{Determination of nitric oxide formation}

NO release was determined spectrophotometrically using microplate reader on the basis of accumulation of nitrite in the medium. Nitrite levels were determined using the Griess reagent. ${ }^{15}$ Standards contained known quantities of $\mathrm{NaNO}_{2}$ in the buffer.

\section{Determination of ammonium formation}

Determination of ammonium using a microplate-based fluorometric technique ${ }^{16,17}$ included using of working reagent, consisting of $750 \mathrm{mM}$ o-ftalic aldehyde and $72 \mathrm{mM} \mathrm{b}$-mercaptoethanol in ethanol, and $200 \mathrm{mM}$ sodiumpotassium phosphate buffer (1:1:18). Standards contained known quantities of $\mathrm{NH} 4 \mathrm{Cl}$ in the buffer.

Assays with each product were performed in triplicate. Data were analyzed by Student's ttest to determine statistical differences of the means. Data were presented as means \pm s.e.m. A value of $\mathrm{P}<0.05$ was considered to indicate statistical significance.

\section{Results and Discussion}

Previously we found that the mass of highmetabolic-rate organ liver was smaller in rats after subchronic semicarbazide consumption with drinking water (6.7 $\mathrm{mM}$ for 45 days) as compared to controls. Furthermore, the results of electron paramagnetic resonance spectroscopy revealed ferric heme iron enhancement by $20 \%$ (signals with $\mathrm{g}=2.25$ and 2.42 ) in liver CYP-450s that may be indicative of sufficient activation of liver monooxiganase system in reply to prolonged xenobiotic introduction if takes into account the existence of powerful cytochrome-heme-reducing system. ${ }^{3}$ Thus, liver monooxiganase system was suspected to substantially participate in the metabolic activation of semicarbazide and consequently could induce the tissue destraction. Presently the ability of rat liver microsomes to metabolize the potential carcinogen SC was investigated using in vitro approach. The work was undertaken to characterize the SC metabolization mechanism by identifying its basic products. Taking in consideration SC structural formula, the existence of two main ways of its decomposition may be supposed. The hypothesis is illustrated in Figure 1. The oxidation products may include $\mathrm{FA}$, as well as ammonium and NO.

We supposed that members of CYP family 
may take part in this process. Cytochrome P450 is a superfamily of enzymes responsible for detoxifying exogenous compounds. The function of most CYP enzymes is to catalyse the oxidation of organic substances. The substrates of CYP enzymes include metabolic intermediates, as well as xenobiotic substances such as drugs and other toxic chemicals. CYPs are the major enzymes involved in drug metabolism and bioactivation, accounting for $\sim 75 \%$ of the total number of different metabolic reactions. The most common reaction catalyzed by cytochromes P-450 is a monooxigenase reaction, e.g., insertion of one atom of oxygen into an organic substrate $(\mathrm{RH})$ while the other oxygen atom is reduced to water:

$$
\mathrm{RH}+\mathrm{O}_{2}+2 \mathrm{H}^{+}+2 \mathrm{e}-\mathrm{ROH}+\mathrm{H}_{2} \mathrm{O}
$$

These xenobiotic-metabolizing enzymes not only detoxify xenobiotics but also cause the formation of active intermediates, which in certain circumstances may elicit a diversity of toxicities, including mutagenesis, carcinogenesis and hepatic necrosis. Recently, there are no available toxicological data to make conclusion about possible semicarbazide induction of lesions in the hepatocytes. At the same time the hydrazine, as SC precursor was cytotoxic as measured by leakage of lactate dehydrogenase and caused depletion of ATP, and inhibited protein synthesis in cultured rat hepatocytes. The threshold cytotoxic concentration was $20 \mathrm{mM}$. Inhibition of protein synthesis was detected at a much lower concentration of hydrazine $(0.5 \mathrm{mM})$ than was required to deplete ATP $(16 \mathrm{mM})$ or cause cytotoxicity (20 $\mathrm{mM}) .{ }^{18}$ To approve the hypothesis of liver CYP450 s participation in SC metabolization we used difference spectrophotometry approach. When studying substrate binding to the CYP450 s, the heme prostetic group often serves as a very useful chromophore that can be exploited for characterization purposes. Because oxidation of CYP-450-bound substrate occurs at the heme, certain aspects of substrate binding can be monitored readily with spectrophotometer, e.g. the signature manners in which the CYP-450s heme spectra are altered. Three fundamentally empirical types of spectra have been well characterized for binding of drugs and other chemicals to hepatic microsomal cytochromes P-450: type I, with spectral maxima about 385 or $390 \mathrm{~nm}$ and minima about 420 $\mathrm{nm}$; type II, with minima about 390 or $410 \mathrm{~nm}$ and maxima about 427 to $430 \mathrm{~nm}$; and reverse to typeI, which is almost exactly the mirror image of tipeI spectra. Most CYP-450s are lowspin in the substrate-free form. Binding of substrate shifts the low-spin state to the highspin state and the Soret absorption band, resulting in the type I difference spectrum. This shift is associated with the transformation of the cytochrome from an inactive to the active reducible intermediate of the catalytic cycle. We used the technique of difference spectrophotometry to study spectral changes which represent the binding of SC to hepatic microsomal cytochrome P-450. Spectra were recorded after addition of $\mathrm{SC}$, and a difference spectrum was computed by subtraction of the starting spectrum from those generated at each selected time point. The filtration procedures of MultiCONTM processor were used for obtaining clean difference visible spectra. The maximum apparent absorption change induced at each chosen time point was determined by subtraction of the minimum absorption value at the through in each difference spectrum from the maximum value at the peak (using data at the same wavelength, 420 and $390 \mathrm{~nm}$ ). The statistical accuracy of the spectral calculation methods allows us to identify new spectral features.

Spectral changes in CYP-450s of rat liver microsomes during interaction with $\mathrm{SC}$ in the range of concentrations from $0.05 \mathrm{mM}$ to 10 $\mathrm{mM}$ were recorded. As an example, calculated difference spectra of microsomes with $3 \mathrm{mM}$ SC are represented in Figure 2 as compared with spectra of substrate-free microsome CYP450s in Figure 3. Cytochrome P-450 of the liver

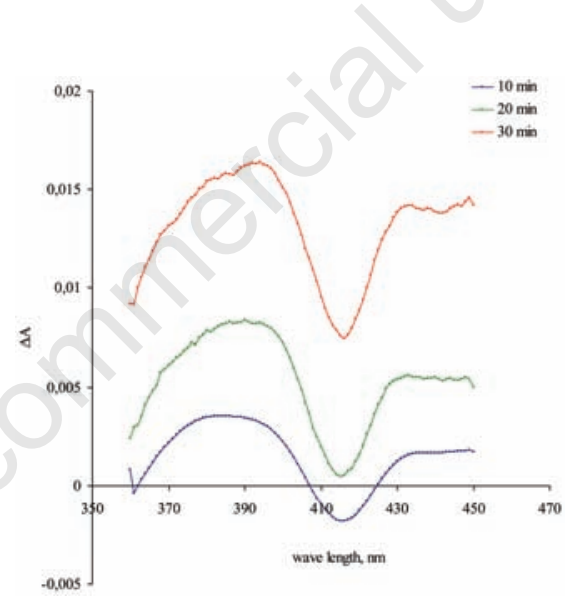

Figure 2. Difference spectra of rat liver microsomes in $10 \mathrm{mM}$ Tris- $\mathrm{HCl}$ buffer $(\mathrm{pH}$ 7.2), containing $3 \mathrm{mM}$ semicarbazide.

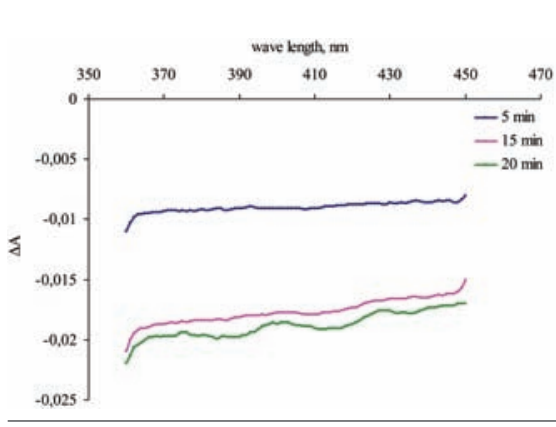

Figure 3. Difference spectra of substratefree rat liver microsomes CYP- 450 . microsomes of rats after interaction with SC gave a maximum of absorption at 390 and a minimum at $420 \mathrm{~nm}$, characteristic typeI difference spectrum which reflects both the substrate binding to the active site of CYP-450 and transformation of the cytochrome to the active intermediate of the catalytic cycle. These spectral changes are linear with time under the concentration range of SC 1.5-7.5 mM (Figures $4,5)$, whereas lower SC concentrations $(0.05$ $0.3 \mathrm{mM}$ ) did not induce characteristic type I spectral changes. On this reason we used $\mathrm{mM}$ concentration of $\mathrm{SC}$ in our subsequent investigations.

In order to additionally approve our hypoth-

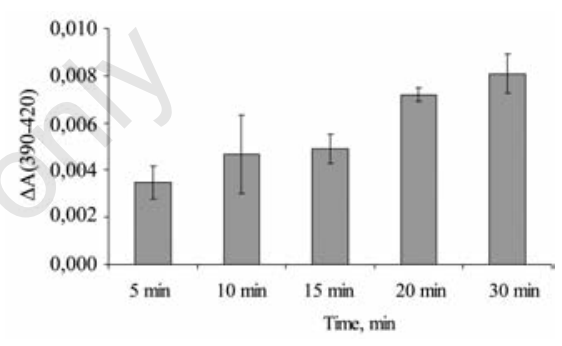

Figure 4. Time dependence of maximum apparent absorption change in rat liver microsomes CYP-450s with $3 \mathrm{mM}$ semicarbazide.

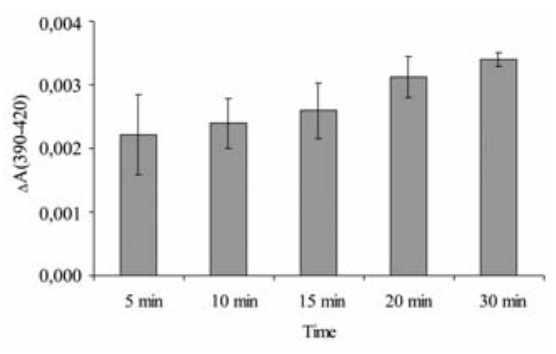

Figure 5. Time dependence of maximum apparent absorption change in rat liver microsomes CYP-450s with $7.5 \mathrm{mM}$ semicarbazide.

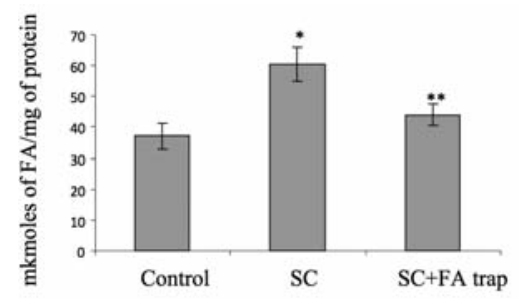

Figure 6. Formaldehyde (FA) formation by rat liver microsomes during semicarbazide (SC) metabolization for 15 minutes $\left({ }^{*} \mathbf{P}<\mathbf{0 . 0 1}\right.$ relative to control, ${ }^{* *} \mathbf{P}<\mathbf{0 . 0 5}$ relative to semicarbazide). 
Table 1. Analysis of metabolization products of semicarbazide and nitrosamine by rat liver microsomes

\begin{tabular}{lcc} 
Substrate & \multicolumn{2}{c}{$\begin{array}{c}\text { Products detected, } \\
\text { fumol/min/mg protein }\end{array}$} \\
& Formaldehyde & Nitrite \\
N-nitrosodimethylamine & $2.43 \pm 0.78(5)$ & $1.68 \pm 0.68(4)$ \\
Semicarbazide & $1.47 \pm 0.47(7)$ & $0.75 \pm 0.13(4)$ \\
\hline
\end{tabular}

Results are expressed as the means \pm standard error; numbers of observations are in parentheses.

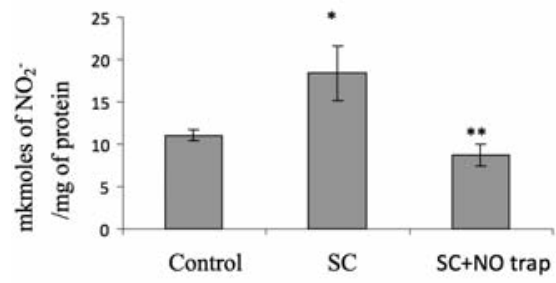

Figure 7. Nitrite formation by rat liver microsomes during semicarbazide metabolization for 15 minutes $\left({ }^{*} \mathrm{P}<0.01\right.$ relative to control, ${ }^{* *} \mathrm{P}<\mathbf{0 . 0 5}$ relative to semicarbazide)

esis we used NDMA, well known CYP-450s substrate, along with SC. Using the same concentrations of reagents as in in vitro study ${ }^{6}$ we showed that rates of FA, as well as NO formation during the reaction with NDMA and SC decomposition were of the same order (Table 1). In Table 1 the detected rates of FA and NO production for both SC and NDMA are shown. Data show that FA and NO were formed when $5 \mathrm{~mm}$ NDMA or $7.5 \mathrm{mM} \mathrm{SC}$ were incubated with rat liver microsomes. These data in an indirect way approve our assumption.

Formation of FA was monitored by the Nash method as mentioned in materials and methods. The presence of FA in the reaction mixture was additionally confirmed by trapping FA with dimedone (Figure 6). The results demonstrate that FA was produced to the extent of $22.04 \pm 7.1 \mathrm{~mol} / \mathrm{mg}$ protein (compared to control) within 15 min during $\mathrm{SC}$ transformation, whereas dimedone presence sufficiently decreased this quantity (more than twice). Clinically, the lethal dose of formaldehyde for human beings is about $0.08 \%$ in the circulation. Although the hepatic changes are generally not extensive and can be reversible following acute exposure, the potential exists for them to progressively become more serious with repeated exposures at concentrations even lower than $0.08 \%$, the clinical dose of toxicosis. There are several possible mechanisms for the toxicity. Depending on the route of exposure, these could include direct effects on hepatocytes and/or indirect effects through the circulatory and immune systems.

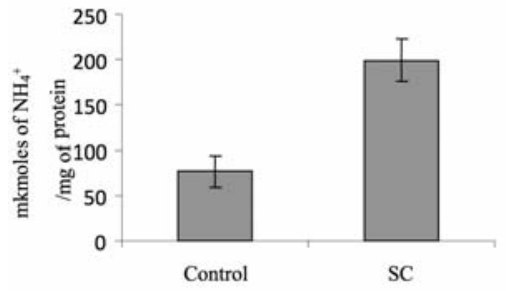

Figure 8. Ammonium formation by rat liver microsomes during semicarbazide metabolization for 15 minutes $\left({ }^{*} \mathrm{P}<0.01\right.$ relative to control, ${ }^{* *} \mathrm{P}<0.05$ relative to semicarbazide)

The mean increase in nitrite concentration in $15 \mathrm{~min} \mathrm{SC}$ incubation with microsomes was smaller than that of FA $(11.29 \pm 1.91 \mathrm{~mol} / \mathrm{mg}$ protein, compared to control). To determine whether NO might have been produced as SC product, $\mathrm{SC}$ was incubated with rat liver microsomes in the presense of potent NO trap diethyldithiocarbamate-Fe ${ }^{+2}$ complex (Figure 7). Again, the $\mathrm{NO}_{2}$ concentration decreased significantly under these conditions. We conclude, therefore, that NO is produced directly in the reaction. This simple diatomic molecule is capable of attacking the iron-sulphur components of electron-transfer proteins. The reaction of NO with iron-sulphur clusters leads to disassembly of the cluster and formation of various new iron compounds referred to as dinitrosyl iron complexes. The destruction of proteins containing these iron-sulphur clusters constitutes a mechanism of toxicity and can lead to diseased states. NO may also play a role in controlling hepatic lipid peroxidation. Nitric oxide is a highly reactive oxidant known to interfere with hepatocyte protein and DNA synthesis, and its production by these cells may lead to cytotoxicity and apoptosis, thus contributing to tissue injury.

Measurements of ammonium by 0-phthaldialdehyde reagent showed sufficient ammonium concentrations change with respect to the control, more than twice, in 15 min (Figure 8). But in this case the extent of ammonium production was 10 -fold greater than that of nitrite and FA, the fact, which could not be explained recently. Ammonia is also highly toxic.
Normally blood ammonium concentration is $<50 \mu \mathrm{mol} / \mathrm{L}$, and an increase to only $100 \mu \mathrm{mol} / \mathrm{L}$ can lead to disturbance of consciousness. A blood ammonium concentration of $200 \mu \mathrm{mol} / \mathrm{L}$ is associated with coma and convulsions.

The quantitative outcome of this experiment indicates a roughly equimolar correspondence between FA and NO as products of SC decomposition. In our opinion, the mechanism of $\mathrm{SC}$ toxic action involves the generation of hazardous products by liver CYP-450s, the reasons of pathological state for many diseases. Further investigations are necessary to evaluate the influence of SC in lower concentrations on hepatocytes viability and contribution of different members of CYP-450s family in SC metabolization using inhibitory approach.

\section{References}

1. Zernov AI, Lisitsin MS, Popov VI, et al. Results in the treeatment of cancer patients with semicarbaside and cadmium. Vopr Onkol 1963;18:114-16. [Article in Russian]

2. Roessner V, Uebel H, Becker A, et al. Serum level of semicarbazide-sensetive amine oxidase in children with ADHD. Behav Brain Funct 2006;2:5.

3. Dmytrenko MP, Shandrenko SG, Petrun LM, et al. Formaldehyde metabolism in semicarbazide intoxication. Ukr Biokhim Zh. 2010; 82:86-91. [Article in Ukrainian]

4. Carlton WW, Hunt CE, Newberne PM. Neural lesions induced in ducklings by isonicotinic acid hydrazide and semicarbazide hydrochloride. Exp Mol Pathol 1965; 4:438-48.

5. Lyles GA, McDougall SA. The enhanced daily excretion of urinary methylamine in rats treated with semicarbazide or hydrazine may be related to the inhibition of semicarbazide-sensitive amine oxidase activities. J Pharm Pharmacol 1989;41:97100.

6. Kroeger-Koepke MB, Koepke SR, McClusky $\mathrm{GA}$, et al. -Hydroxylation pathway in the in vitro metabolism of carcinogenic nitrosamines: N-Nitrosodimethylamine and $\mathrm{N}$ nitroso-N-methylaniline. Proc Natl Acad Sci USA 1981;78:6489-93.

7. $\mathrm{Yu} \mathrm{PH}$, Wright $\mathrm{S}$, Fan $\mathrm{EH}$, et al. Physiological and pathological implications of semicarbazide-sensitive amine oxidase. Biochim Biophys Acta 2003;1647: 193-9.

8. Pema PJ, Horak HA, Wyatt RH. Myelopathy caused by nitrous oxide toxicity. AJNR Am J Neuroradiol 1998;19:894-6.

9. Denk H, Moldeus PW, Schulz RA, et al. Hepatic organelle interaction. IV. Mecha- 
nism of succinate enhancement of formaldehyde accumulation from endoplasmic reticulum N-dealkylations. J Cell Biol 1976;69:589-98.

10. Lizcano JM, Tipton KF, Unzeta M. Purification and characterization of membrane-bound semicarbazide-sensitive amine oxidase (SSA0) from bovine lung. Biochem J 1998; 331:69-78.

11. Bradford MM. A rapid and sensitive method for the quantitation of microgram quantities of protein utilizing the principle of protein-dye binding. Anal Biochem 1976;72:248-54.

12. Sárdi E, Tyihák E. Relationship between dimedone concentration and formaldehyde captured in plant tissues. Acta Biol Hung 1998; 49:291-301.

13. Yoshimura T, Kotake Y. Spin trapping of nitric oxide with the iron-dithiocarbamate complex: chemistry and biology. Antiox Redox Signal 2004;6:639-47.

14. Nash T. The colorimetric estimation of formaldehyde by means of the hantzsch reaction. Biochem J 1953;55:416-21.

15. Ghasemi A, Hedayati, Biabani H. Protein precipitation methods evaluated for determination of serum nitric oxide end products by Griess assay. JMSR 2007;2:30-1.

16. Davis LC, Radke GA. Chemically coupled spectrophotometric assays based on flow injection analysis: determination of nitrogenase by assays for creatine, ammonia, hydrazine phosphate and ditionite. Anal Biochem 1984;40:434-42.

17. Poulin P, Pelletier È. Determination of ammonium using a microplate-based fluorometric technique. Talanta 2007;71:15006.

18. Ghatineh S, Timbrell JA. Hydrazine toxicity in isolated hepatocytes in suspension and primary culture. Biochem Soc Trans 1990;18:1217-8. 